\title{
Retain the Original, Maintain Harmony_-Management of Avulsion: A Case Report
}

\author{
Hana Hameed ${ }^{1}$, Praveena Geetha ${ }^{2}$, Kunjusankaran Radhakrishnan Nair ${ }^{3}$, Remya Cauvery ${ }^{4}$
}

\begin{abstract}
Background: Tooth avulsion is the complete displacement of a tooth out of the alveolar socket. The lack of immediate treatment measures can result in the loss of function, esthetics, psychological and social problems, and poor quality of life. Several factors may not enable the prompt replantation of an avulsed tooth; hence, delayed replantation has emanated as an alternative to meet the esthetic, functional, and psychological demands of the patients.

Case description: This case report details the replantation of an avulsed maxillary central incisor in a 21-year-old male patient which was replanted 2 hours after the event. Extraoral root canal treatment was done before replantation and follow-up examinations were performed during 1, 3, and 6 months. The tooth remained in a stable functional position and did not reveal any pathological changes after 6 months. Both esthetic and functional outcomes were satisfactory.

Conclusion: The extent of damage to the tooth and supporting structures, emergency management, and follow-up treatment play a role in the prognosis of the avulsed tooth. The tooth was kept in saline before replantation, and 6 months follow-up showed a favorable prognosis, and further evaluation is needed to predict the long-term prognosis of the tooth.

Keywords: Avulsion, Extraoral root canal treatment, Replantation, Splinting, Storage media.

Conservative Dentistry and Endodontic Journal (2019): 10.5005/jp-journals-10048-0053
\end{abstract}

\section{INTRODUCTION}

Avulsion is one of the most severe dentoalveolar injuries, where the tooth or teeth are completely displaced from its socket. This injury accounts for between $0.5 \%$ and $3 \%$ of dentoalveolar trauma to permanent teeth. ${ }^{1}$ The common causes for traumatic dental injuries in childhood are sporting injuries, accidental falls, cycling accidents, and assault. ${ }^{2,3}$ The most frequently avulsed teeth are the maxillary central incisors.

In most situations, the avulsed permanent tooth should be replanted as quickly as possible ideally within the first 90 minutes. Extraoral time of the tooth, between avulsion and replantation, is an important factor which influences the prognosis of the replanted tooth., ${ }^{4,5}$

Emergency care includes how the tooth was stored before replantation, replantation, and splinting. To minimize infection and to alter the inflammatory response, systemic or topical antibiotics or both are prescribed. The best treatment at the place of accident is prompt replantation. Once the tooth is replanted, to hold it in position, the patient should bite on a handkerchief. When it is not possible to replant the avulsed tooth, it should be placed in a glass of milk or another suitable storage medium and taken with the patient to the emergency clinic. The tooth can be transported in the mouth, keeping it inside the lip or cheek if the adult patient is conscious. ${ }^{5}$

When assessing interventions for tooth avulsion, periodontal ligament healing is the primary outcome measure for long-term survival of the tooth. Clinical interventions can include reducing infection or modifying the inflammatory response or both, since both infection and inflammatory response can reduce the chances of periodontal ligament healing, leading to replacement root resorption. According to Borum and Andreasen, the risk of pulp necrosis is $92 \%$ in avulsed teeth. Considering the results of previous studies, the prevalence of ankylosis ranges between $57 \%$ and $80 \%$ in avulsed and replanted teeth. ${ }^{6}$ The survival of the tooth
${ }^{1-4}$ Department of Conservative Dentistry and Endodontics, Azeezia College of Dental Sciences and Research, Kollam, Kerala, India

Corresponding Author: Hana Hameed, Department of Conservative Dentistry and Endodontics, Azeezia College of Dental Sciences and Research, Kollam, Kerala, India, Phone: +91 9995359286, e-mail: zahrazayed@gmail.com

How to cite this article: Hameed H, Geetha P, Nair KR, et al. Retain the Original, Maintain Harmony-Management of Avulsion: A Case Report. Cons Dent Endod J 2019;4(2):53-55.

Source of support: Nil

Conflict of interest: None

directly depends on the stage of root development at the time of replantation. According to the studies comparing the survival rates of teeth with open and closed apices after avulsion injury, immature permanent teeth with open apices indicate lower survival in comparison with teeth with closed apices. ${ }^{7}$

The purpose of this case report is to describe the delayed replantation of an avulsed permanent maxillary central incisor in a 21-year-old male patient with a history of fall. Clinical and radiological examination was done for 6 months to evaluate the prognosis.

\section{Case Description}

A 21-year-old male patient reported to the department with an avulsed upper central incisor. He had slipped and fallen at his door step, hitting his face, leading to the tooth falling off. After the trauma, the patient had reported to a dental clinic with the tooth held in hand, in an hour, from where he was referred to the college with the tooth placed in a plastic container immersed in saline. He took another 30 minutes to reach the college. Medical 
history was uneventful. Extraoral examination showed no signs or symptoms of neurological or extraoral injury. No other oral injury was detected clinically. Intraoral examination revealed missing maxillary right central incisor (11) (Fig. 1).

The crown portion of 11 was fractured at the incisal third, and the root was intact. The adjacent teeth were nontender, and mobility was within normal limits and responded normally to vitality tests. Since the patient reported to the clinic after an hour it was decided to do root canal treatment before replantation. The tooth was held gently in a gauze soaked in saline. Access cavity was prepared, working length established, and the root canal was prepared biomechanically followed by immediate obturation. The access opening was temporarily sealed with zinc oxide eugenol cement. Local anesthesia was administered. The socket was gently irrigated with saline. The tooth with a clean root surface was placed back in the socket with light digital pressure. It was secured in place, and the position was verified radiographically. Occlusal clearance was ensured, and the replanted tooth was stabilized with the help of semirigid splint with braided stainless steel ligature wire and composite resin (Figs $2 \mathrm{~A}$ and 3 ).

Tetanus prophylaxis was administered; soft diet was advised for 2 weeks; and chlorhexidine mouthwash, antibiotics, and analgesics were prescribed (tablet augmentin $625 \mathrm{mg}$ bid $\times 5$ days and tablet dichloran $A$ tid $\times 3$ days). At the end of 4 weeks, the patient showed

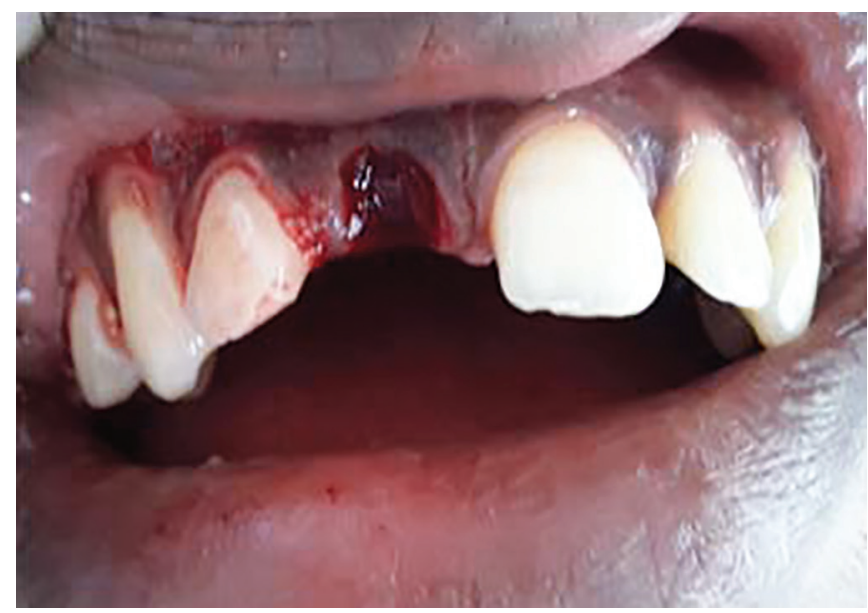

Fig. 1: Preoperative intraoral photograph

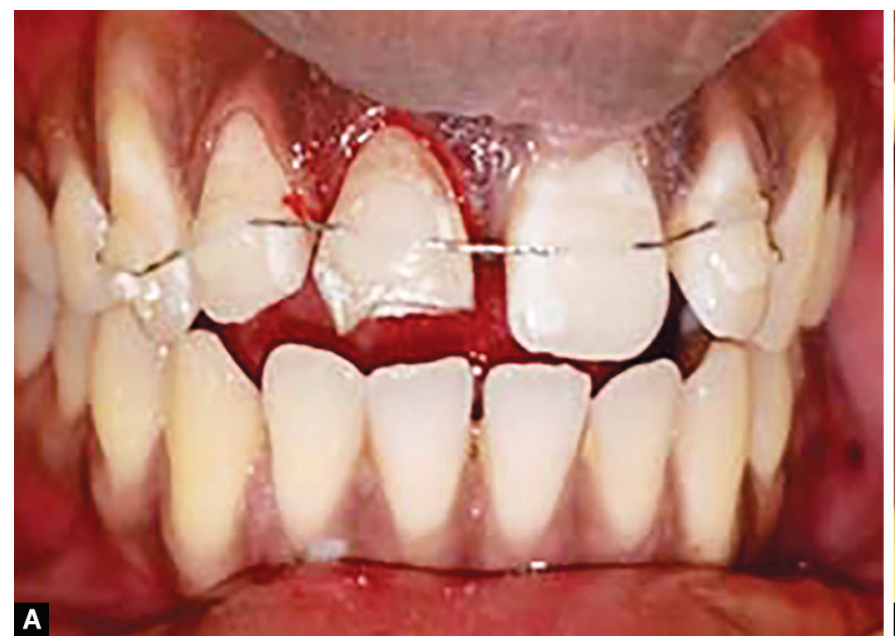

Figs 2A and B: (A) Immediate postoperative photograph; (B) Intraoral photograph of 6 months follow-up no negative symptoms or signs. Mobility was within normal limits, and the splint was removed. Postendodontic restoration was done with composite after placing glass ionomer cement (GIC) base. Clinical examination during 1, 3, and 6 months follow-up showed no pain on percussion and palpation or mobility. There was no evidence of root resorption radiographically. The adjacent teeth responded normally to vitality test (Figs $2 \mathrm{~B}$ and 4 ).

\section{Discussion}

The long-term fate of replanted teeth is not predictable; it is dependent on various factors, such as the time interval between avulsion and replantation, extra-alveolar storage period, the vitality status of pulp or periodontal tissues, and the type and period of splinting.

Hanks' balanced salt solution and pasteurized milk are the most appropriate clinically recommended storage media. Eagle's culture medium, Viaspan, propolis, green tea, egg white, and coconut water are other suitable storage media. ${ }^{8}$ Normal saline has balanced osmolality, and despite being compatible with the cells of the periodontal ligament, it lacks essential nutrients such as magnesium, calcium, and glucose which are fundamental to normal metabolic needs of the cells of the periodontal ligament. It is suitable for short-term storage of avulsed teeth for about 2 hours, and it is potentially damaging if the cells are stored for longer than this. Hence, saline is not an ideal storage medium; however, it may be employed for short period of time, when other storage media are not immediately available.

The goal in delayed replantation is restoring the tooth for esthetic, functional, and psychological reasons and to maintain alveolar bone contour. In a tooth with a closed apex, the pulp will begin to experience cellular necrosis within an hour. The pulp may soon become infected and progress to inflammatory root resorption. As per International Association of Dental Traumatology (IADT) guidelines if the extraoral dry time of the avulsed tooth is longer than 60 minutes, the root canal treatment to the tooth can be carried out before replantation or later. In this case, since the tooth has been stored dry for almost 60 minutes, the root canal treatment was carried out extraorally before replantation. ${ }^{5}$ It is necessary to splint the replanted tooth to the adjacent teeth flexibly for 2 weeks for periodontal healing. Studies have shown that periodontal and pulpal healing is promoted if the replanted tooth is given a chance

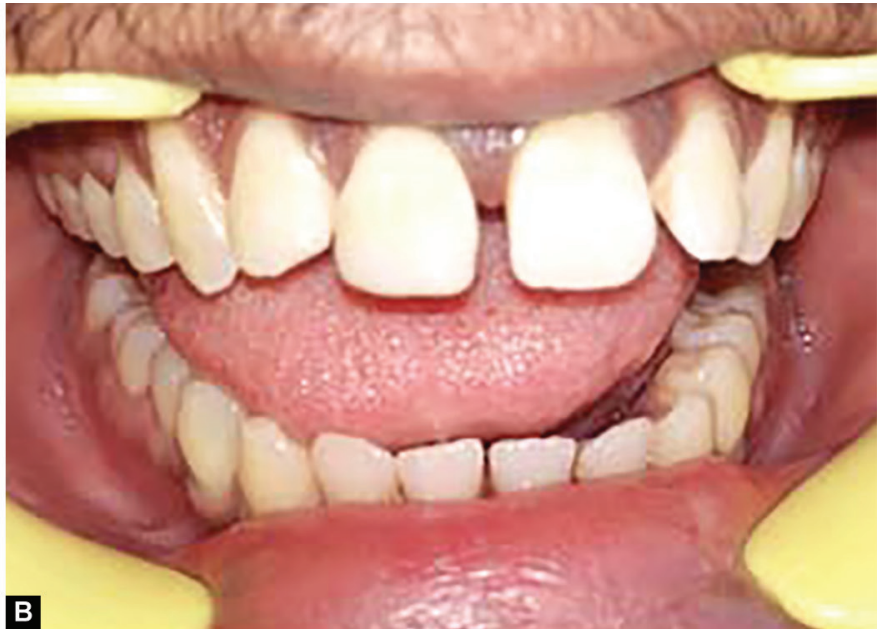




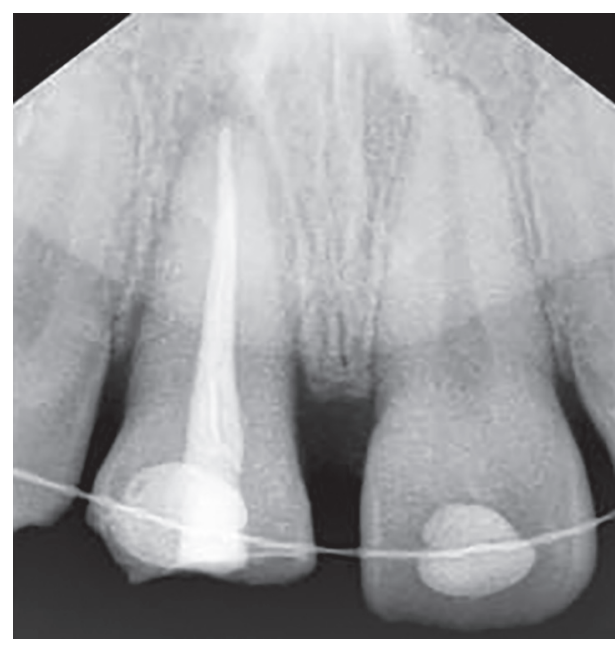

Fig. 3: Immediate postoperative radiograph

for slight motion and the splinting time is not too long. ${ }^{9}$ As per IADT guidelines, tooth which has been root canal treated before replantation should be splinted for 4 weeks, and hence, splinting was done accordingly. The use of semirigid splint is indicated than the rigid one. The splint should have no shape memory so that the tooth is not moved during healing and should not impinge on the gingiva which will prevent the maintenance of oral hygiene in the area. ${ }^{10}$

The tooth would have been exposed to bacterial contamination extraorally and intraorally. The use of antibiotics reduces the bacterial inflammatory stimulus. This may have some role in improving periodontal and pulpal healing. The esthetic and functional properties can be maintained by the avulsed tooth for some years after the replantation. In this case from a clinical point of view, the viability of the periodontal ligament cells may be minimal since the total extraoral dry time was almost 60 minutes regardless of the tooth being stored in saline. The longterm prognosis of delayed replantation is poor. The periodontal ligament will be necrotic and not expected to heal. However, 6 months follow-up showed a favorable prognosis which may be due to the use of a storage media, good immune status of the patient, intact surrounding soft tissues, and alveolar bone. Although root resorption and ankylosis occur mostly in the first year after replantation, the mentioned complications can also be seen in later periods. ${ }^{11}$ Therefore, long-term follow-up is essential for the replantation cases.

\section{Conclusion}

According to the findings of the presented case, replantation can be advised for avulsed tooth with prolonged extraoral time after endodontic treatment. Although extraoral time is an important factor, other factors such as suitable storage media, health, and age of the patient may affect the prognosis of the replanted tooth. Although the tooth had an extraoral time of nearly 60 minutes before it was stored in saline, and replanted after 90 minutes, we could get a favorable prognosis even after 6 months. The patient's intact surrounding soft tissues and alveolar bone may

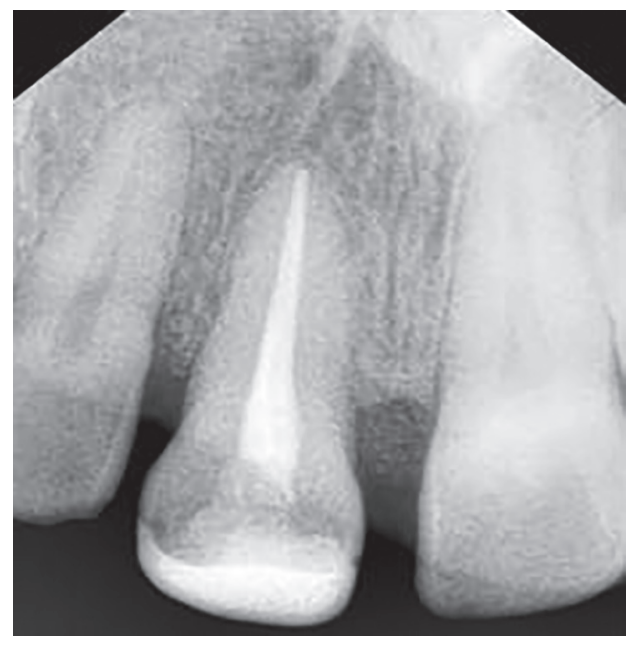

Fig. 4: Radiographic image -6 months review

have favored healing. However, the risk of resorption at long-term should be considered.

\section{References}

1. AndreasenJO,AndreasenFM.Avulsions.In:Andreasen JO,AndreasenFM, Andersson $L$, ed. Textbook and color atlas of traumatic injuries to the teeth. 4th ed., Copenhagen: Blackwell Munksgaard; 2007. pp. 444-488.

2. Gulinelli J, Saiton C, Garcia-Junior I, et al. Occurrence of tooth injuries in patients treated in hospital environment in the region of Aracatuba, Brazil during a 6-year period. Dent Traumatol 2008;24(6):640-644. DOI: 10.1111/j.1600-9657.2008.00673.x.

3. Wright G, Bell A, McGlashan G, et al. Dentoalveolar trauma in Glasgow: an audit of mechanism and injury. Dent Traumatol 2007;23(4): 226-231. DOI: 10.1111/j.1600-9657.2006.00430.x.

4. Day PF, Gregg TA. Treatment of avulsed permanent teeth in children. UK National Clinical Guidelines in Paediatric Dentistry. Fac Dent J 2012;3:166-169. DOI: 10.1308/204268512X13376834221677.

5. Andersson L, Andreasen JO, Day P, et al. International Association of Dental Traumatology guidelines for the management of traumatic dental injuries: 2. Avulsion of permanent teeth. Dent Traumatol 2012;28(2):88-96. DOI: 10.1111/j.1600-9657.2012.01125.x.

6. Zaleckiene V, Peciuliene V, Brukiene V, et al. Traumatic dental injuries: etiology, prevalence and possible outcomes. Stomatologija 2014;16(1):7-14.

7. Petrovic B, Marković D, Peric T, et al. Factors related to treatment and outcomes of avulsed teeth. Dent Traumatol 2010;26(1):52-59. DOI: 10.1111/j.1600-9657.2009.00836.x.

8. Khinda VIS, Kaur G, Brar GS, et al. Clinical and practical implications of storage media used for tooth avulsion. Int J Clin Pediatr Dent 2017;10(2):158-165. DOI: 10.5005/jp-journals-10005-1427.

9. Veras SRA, Bem JSP, Almeida ECB, et al. Dental splints: types and time of immobilization post tooth avulsion. J Istanb Univ Fac Dent 2017;51(3 Suppl 1):S69-S75. DOI: 10.17096/jiufd.93579.

10. Von Arx T, Filippi A, Buser D. Splinting of traumatized teeth with a new device. TTS (titanium trauma splint). Dent Traumatol 2001;17(4): 180-184. DOI: 10.1034/j.1600-9657.2001.170408.x.

11. Andreasen JO, Borum MK, Jacobsen HL, et al. Replantation of 400 avulsed permanent incisors 4 factors related to periodontal ligament healing. Endod Dent Traumatol 1995;11(2):76-89. DOI: 10.1111/j.16009657.1995.tb00464.x. 